Check for updates

Cite this: Phys. Chem. Chem. Phys., 2021, 23, 13338

Received 25th January 2021, Accepted 30th May 2021

DOI: $10.1039 / \mathrm{d} 1 \mathrm{cp} 00360 \mathrm{~g}$

rsc.li/pccp

\section{Using computational chemistry to design pump-probe schemes for measuring nitrobenzene radical cation dynamics $\dagger$}

\author{
Hugo A. López Peña, Derrick Ampadu Boateng, Shane L. McPherson and \\ Katharine Moore Tibbetts (D)*
}

\begin{abstract}
The electronic potential energy surfaces of the nitrobenzene cation obtained from time-dependent density functional theory and coupled cluster calculations are used to predict the most efficient excitation wavelength for femtosecond time-resolved mass spectrometry measurements. Both levels of theory identify a strongly-coupled transition from the ground state of the nitrobenzene cation with a geometry-dependent oscillator strength, reaching a maximum at $90^{\circ} \mathrm{C}-\mathrm{C}-\mathrm{N}-\mathrm{O}$ dihedral angle with a corresponding energy gap of $\sim 2 \mathrm{eV}$. These results are consistent with the experimental observation in the nitrobenzene cation of a coherent superposition of vibrational states: a vibrational wave packet. Time-resolved measurements using a probe wavelength of $650 \mathrm{~nm}$, nearly resonant with the strong transition, result in enhanced ion yield oscillation amplitudes as compared to excitation with the nonresonant $800 \mathrm{~nm}$ wavelength. Analogous behavior is found for the closely related molecules 2- and 4-nitrotoluene. These results demonstrate that computational chemistry can predict the best choice of probe wavelength in time-resolved measurements of vibrational coherent states in molecular cations.
\end{abstract}

\section{Introduction}

Polyatomic radical cations are highly reactive species that contribute to many physical, chemical, and biological processes. For instance, radical cations and anions participate in shock initiation of detonated energetic materials used as explosives and propellants; ${ }^{1}$ generation of radical cations in DNA nucleobases and the sugar-phosphate backbone upon exposure to ionizing radiation induces DNA damage; ${ }^{2}$ and radical cations of polycyclic aromatic hydrocarbons (PAHs) undergo numerous reactions that form other complex molecules in the interstellar medium. ${ }^{3}$

Intense femtosecond laser excitation coupled to mass spectrometry has been used for decades to study dissociation in radical cations because the short pulse duration induces rapid ionization prior to dissociative electronic excited state population, resulting in less molecular fragmentation. ${ }^{4}$ In particular, excitation with near-infrared wavelengths $(\sim 1200-1600 \mathrm{~nm})$ is widely observed to suppress fragmentation compared to excitation with the $800 \mathrm{~nm}$ Ti:Sapphire wavelength. ${ }^{5-11}$ The high yield of intact

Department of Chemistry, Virginia Commonwealth University, Richmond, VA 23284, USA.E-mail:kmtibbetts@vcu.edu

$\dagger$ Electronic supplementary information (ESI) available: Supplemental figures of theory benchmarking and experimental curve fitting; tabulated theoretical results and curve fitting coefficients. See DOI: 10.1039/d1cp00360g molecular ion is attributed to increased contribution of adiabatic electron tunneling to the ionization process, thereby enhancing population of the ground electronic state of the cation. ${ }^{6,9}$ However, extensive molecular fragmentation is still observed when the laser wavelength is resonant with an electronic transition between the ground electronic state and an excited state of the cation. ${ }^{7-15}$

Time-resolved pump-probe measurements are widely used to gain insight into how population of electronic excited states in radical cations induces dissociation. ${ }^{16-35}$ Many of these experiments have identified time-dependent oscillations in transient ion yields due to the preparation of a coherent superposition of vibrational states, i.e., a vibrational wave packet, by the pump pulse and its subsequent excitation by the time-delayed probe pulse. ${ }^{16-30}$ Complementary theoretical calculations of the participating electronic potential energy surfaces have uncovered mechanisms of dissociation via wave packet excitation. For instance, wave packet dynamics along the I-C-Br bending coordinate in $\mathrm{CH}_{2} \mathrm{IBr}^{+}$create a dynamic resonance between the $\mathrm{D}_{0}$ and $\mathrm{D}_{3}$ electronic states that results in loss of neutral iodine to form $\mathrm{CH}_{2} \mathrm{Br}^{+} \cdot{ }^{17,18}$ In acetophenone cation, wave packet dynamics along the torsional $\mathrm{CH}_{3} \mathrm{CO}-\mathrm{C}_{6} \mathrm{H}_{5}$ twisting coordinate result in excitation from $\mathrm{D}_{0}$ to $\mathrm{D}_{2}$ at a dihedral angle of $90^{\circ}$, leading to loss of $\mathrm{CH}_{3}$ to form $\mathrm{C}_{6} \mathrm{H}_{5} \mathrm{CO}^{+}{ }^{21,22}$

The known importance of electronic resonances to dissociation of radical cations has motivated the use of resonant probe 
wavelengths in time-resolved measurements, ${ }^{29-35}$ as is common practice in time-resolved studies of dynamics on neutral electronic excited states. ${ }^{36-41}$ Nevertheless, many time-resolved measurements on radical cations use the readily available $800 \mathrm{~nm}$ wavelength for probing cation dynamics. ${ }^{16-27}$ It would stand to reason that selecting the excitation wavelength to be resonant with electronic transitions in radical cations would enhance the amplitudes of the coherent oscillations resulting from vibrational wave packet dynamics. Computations of electronic potential energy surfaces can efficiently predict geometry-dependent electronic transitions in radical cations, ${ }^{17,18,21,22}$ making computational chemistry a potentially powerful tool for designing pump-probe control schemes to measure coherent vibrational dynamics.

In this work, we use time-dependent density functional theory (TDDFT) calculations of the electronic potential energy surfaces of the nitrobenzene (NB) cation to predict the most efficient excitation wavelength and verify this prediction with coupled cluster calculations and time-resolved mass spectrometric measurements. As a common model for nitroaromatic explosives such as 2,4,6-trinitrotoluene (TNT), ${ }^{42,43}$ NB has been subject to mass spectrometry studies using strong-field femtosecond laser excitation, ${ }^{42-45}$ although no time-resolved studies on NB have been reported to the best of our knowledge. We found a strongly-coupled transition in nitrobenzene cation at a $\mathrm{C}-\mathrm{NO}_{2}$ dihedral angle of $90^{\circ}$ with a $\sim 2 \mathrm{eV}$ energy gap, making the transition nearly resonant with $650 \mathrm{~nm}$ excitation. Efficient geometry-dependent excitation at $650 \mathrm{~nm}$ is confirmed in pump-probe measurements, where oscillations in ion yields were enhanced by a factor of $\sim 2-5$ as compared to excitation at $800 \mathrm{~nm}$. Similar enhancement of oscillation amplitudes with $650 \mathrm{~nm}$ excitation is also observed in the cations of the related molecules 2-nitrotoluene and 4-nitrotoluene (2-NT and 4-NT). These results suggest that using computational chemistry to determine the best probe wavelength for time-resolved experiments can enhance the measurement of prepared vibrational coherent states, which is advantageous for coherent control and quantum information applications.

\section{Methods}

\subsection{Theory}

Our density functional theory (DFT) calculations were conducted using Gaussian 16 software ${ }^{46}$ employing the restricted Kohn-Sham formalism for neutral species and the unrestricted formalism for cationic species. We used the BPW $91^{47}$ functional, within the generalized gradient approximation (GGA), for preliminary geometry and ground-state energy calculations alongside with the $6-311 G^{*}$ and $6-311+G^{*}$ basis sets. ${ }^{48}$ After these preliminary calculations, neutral and cation geometries were optimized with the hybrid GGA B3LYP, ${ }^{49,50}$ the hybrid meta-GGA M06, ${ }^{51}$ and the long-range-corrected hybrid GGA CAM-B3LYP ${ }^{52}$ and $\omega \mathrm{B}^{2} \mathrm{XD}^{53}$ functionals in their different combinations with the $6-311+\mathrm{G}^{*}{ }^{48}$ CBSB7, ${ }^{54}$ AUG-cc-pVDZ, ${ }^{55}$ and Def2TZVPP ${ }^{56}$ basis sets. The convergence threshold for total energy was set to $10^{-8} \mathrm{eV}$ while the force threshold was set to $10^{-3} \mathrm{eV} \AA^{-1}$.
Table 1 Calculated adiabatic and vertical ionization energies for NB and comparison to experimental values in literature, in units of eV. Numbers within parentheses are signed errors with respect to experimental quantities

\begin{tabular}{|c|c|c|}
\hline Method & $\mathrm{IE}_{\mathrm{ad}}$ & $\mathrm{IE}_{\mathrm{vert}}$ \\
\hline B3LYP/6-311+G* & $9.69(0.09)$ & $10.03(0.04)$ \\
\hline B3LYP/CBSB7 & $9.61(0.01)$ & $9.96(-0.03)$ \\
\hline B3LYP/AUG-cc-pVDZ & $9.62(0.02)$ & $9.97(-0.02)$ \\
\hline B3LYP/Def2TZVPP & $9.64(0.04)$ & $9.99(0.00)$ \\
\hline $\mathrm{M} 06 / 6-311+\mathrm{G}^{*}$ & $9.75(0.15)$ & $10.04(0.05)$ \\
\hline M06/CBSB7 & $9.70(0.10)$ & $10.01(0.02)$ \\
\hline M06/AUG-cc-pVDZ & $9.70(0.10)$ & $9.98(-0.01)$ \\
\hline M06/Def2TZVPP & $9.64(0.04)$ & $9.95(-0.04)$ \\
\hline CAM-B3LYP/6-311+G* & $9.89(0.29)$ & $10.13(0.14)$ \\
\hline CAM-B3LYP/CBSB7 & $9.81(0.21)$ & $10.07(0.08)$ \\
\hline CAM-B3LYP/AUG-cc-pVDZ & $9.81(0.21)$ & $11.01(1.02)$ \\
\hline CAM-B3LYP/Def2TZVPP & $9.83(0.23)$ & $10.09(0.10)$ \\
\hline$\omega \mathrm{B} 97 \mathrm{XD} / 6-311+\mathrm{G}^{*}$ & $9.83(0.23)$ & $10.09(0.10)$ \\
\hline$\omega B 97 X D / C B S B 7$ & $9.78(0.18)$ & $10.06(0.07)$ \\
\hline$\omega B 97 X D / A U G-c c-p V D Z$ & $9.75(0.15)$ & $10.95(0.96)$ \\
\hline$\omega B 97 X D / D e f 2 T Z V P P$ & $9.75(0.15)$ & $10.95(0.96)$ \\
\hline BPW91/6-311G* & $9.26(-0.34)$ & $9.61(-0.38)$ \\
\hline BPW91/6-311+G* & $9.36(-0.25)$ & $9.70(-0.29)$ \\
\hline EOM-IP-CCSD/6-311+G* & & $10.06(0.07)$ \\
\hline Expt. & $9.6^{a}$ & $9.99^{b}$ \\
\hline
\end{tabular}

The calculated adiabatic and vertical ionization energies in units of eV, along with comparison to photoelectron spectroscopy experiments ${ }^{57,58}$ are given in Table 1 . The numbers shown within parentheses are the signed errors of calculated values with respect to the corresponding experimental quantities, with negative numbers indicating underestimation and positive numbers indicating overestimation. Clearly, the BPW91 functional used for preliminary calculations performed poorly. Long-rangecorrected hybrid GGA CAM-B3LYP and $\omega$ B97XD functionals overestimated adiabatic and vertical ionization energies in all cases with the combinations CAM-B3LYP/AUG-cc-pVDZ, $\omega B$ B7XD/AUG-ccpVDZ, and $\omega$ B97XD/Def2TZVPP giving deviations around $1 \mathrm{eV}$ from the vertical experimental value. Estimations obtained with the M06 functional agree within 0.15 and $0.05 \mathrm{eV}$ to the experimental adiabatic and vertical values respectively with the M06/Def2TZVPP level of theory giving the most accurate results. The agreement for B3LYP calculations falls within 0.09 and $0.04 \mathrm{eV}$ for adiabatic and vertical quantities with the combinations with the CBSB7, AUG-ccpVDZ, and Def2TZVPP basis sets performing accurate estimations of both experimental quantities. Particularly, the value obtained at the B3LYP/Def2TZVPP level of theory matches the vertical experimental measurement. Due to these reasons we decided to undergo further benchmarking considering the B3LYP and M06 functionals and their combination with the Def2TZVPP basis set.

Additionally, we calculated the vertical ionization energy at the equation-of-motion ionization-potential coupled-cluster singles and doubles (EOM-IP-CCSD) ${ }^{59}$ level in conjunction with the $6-311+\mathrm{G}^{*}$ basis set considering NB optimized geometry at the B3LYP/Def2TZVPP level using Q-Chem 5.3. ${ }^{60}$ The optimized geometries of neutral NB and NB cation obtained at the B3LYP/ Def2TZVPP level of theory are given in the ESI, $\dagger$ Table S1.

The frequencies and intensities of the vibrational modes in both the neutral molecule and the cation were calculated via 


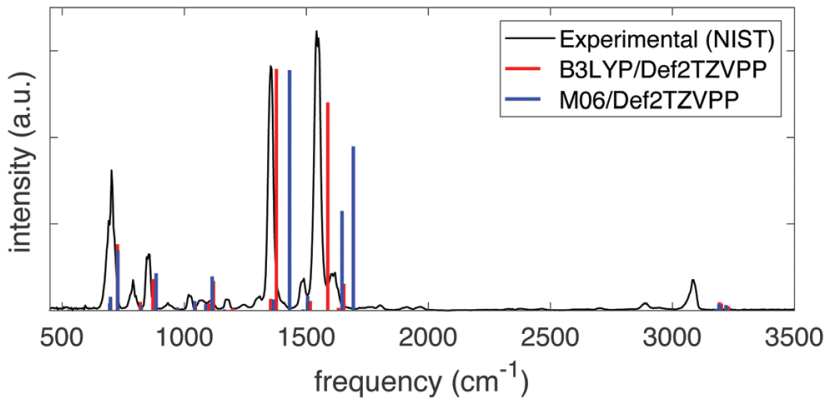

Fig. 1 Experimental (black) and computed infrared spectra at the B3LYP/ Def2TZVPP (red) and M06/Def2TZVPP (blue) levels of theory for NB.

normal mode analysis. In neutral NB, the values of the harmonic vibrational frequencies depended on whether the B3LYP or the M06 functional was used but, given a certain functional, the frequencies and intensities did not depend strongly on the basis set chosen. Fig. 1 shows the comparison between the predicted infrared spectra for the neutral molecule at the B3LYP/Def2TZVPP (red) and M06/Def2TZVPP (blue) levels to the experimental gas-phase spectrum obtained from NIST. ${ }^{61}$ The calculated harmonic frequencies match the experimental peaks reasonably well in the range of $\sim 500-2000 \mathrm{~cm}^{-1}$, but it is evident that the B3LYP/Def2TZVPP level of theory offers the best estimation. This agreement indicates the effectiveness of the method and suggests that the computed cation frequencies should be reasonably accurate. Fig. S1 and S2 of the ESI $\dagger$ show the comparison between the experimental infrared spectrum and the calculated spectra using the B3LYP and M06 functionals in combination with all the basis sets explored in this study. Full tabulated results of the harmonic vibrational frequencies and their corresponding intensities for the neutral molecule and its cation are presented in the ESI, $\dagger$ Tables S3 through S6.

To determine the excited-state energies of the neutral and cationic NB, we performed time-dependent DFT (TDDFT) ${ }^{62}$ calculations using Gaussian 16. We calculated the first 10 singletsinglet (for neutral NB) and doublet-doublet (for NB cation) transitions with the B3LYP and M06 functionals in combination with the above-mentioned four basis sets. We found an analogous behavior to that of simulated IR spectra: the dependence on the functional was stronger than that of the basis set. Fig. 2 shows the comparison of the experimental spectra for NB dissolved in methanol and in chloroform with the calculated ones at the B3LYP/Def2TZVPP and M06/Def2TZVPP levels. Experimental spectra in two solvents (see Section 2.2) are shown to illustrate any solvatochromic effects due to solvent polarity and ensure a reasonable comparison between experimental and calculated spectra. The comparison of the experimental UV-vis spectrum of NB dissolved in methanol with the spectra calculated using B3LYP and M06 functionals in combination with all the basis sets considered in this work can be seen in Fig. S3 of the ESI. $\dagger$ Full tabulated results of the excitation energies and their corresponding oscillator strengths for neutral and cationic NB are presented in Tables S7 through S10 of the ESI. $\dagger$ The better

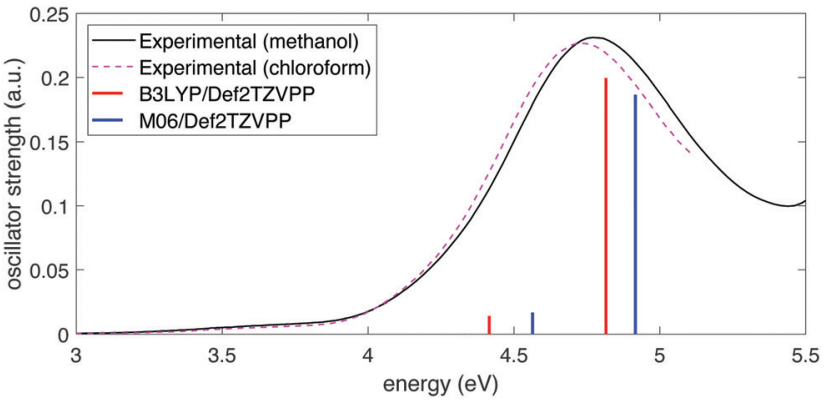

Fig. 2 Experimental UV-vis spectra for NB in methanol (black) and chloroform (dashed magenta) and comparison with computed spectra at the B3LYP/Def2TZVPP (red) and M06/Def2TZVPP (blue) levels of theory.

agreement of the computation at the B3LYP/Def2TZVPP level with the experiment follows in line with the previous benchmarking criteria. Unfortunately, the good performance of the B3LYP/Def2TZVPP level of theory in predicting the excitation spectrum of neutral NB cannot be extrapolated to NB radical cation. In Section 3.1 we will present TDDFT excited-state calculations for NB radical cation at the B3LYP/Def2TZVPP level but those calculations will be further supported with selected calculations at the equation-of-motion excitation-energies coupled-cluster singles and doubles (EOM-EE-CCSD) ${ }^{59}$ level. These EOM calculations were performed using Q-Chem 5.3.

\subsection{Experiment}

The experimental setups have been described in detail in our previous work. $^{23,29,63,64}$ Briefly, a commercial Ti:sapphire regenerative amplifier (Astrella, Coherent Inc.) with a center wavelength of $800 \mathrm{~nm}$, energy of $2 \mathrm{~mJ}$, and pulse duration of $30 \mathrm{fs}$ was used to generate pump and probe beams. Appropriate beam blocks and laser safety goggles were used at all times to minimize hazards of laser beam exposure. The pump beam was taken from the output of a commercial optical parametric amplifier (OPA, TOPAS prime) with the wavelength set to $1300 \mathrm{~nm}$. Two probe beamlines were used: (i) $800 \mathrm{~nm}$, taken from a small portion of the laser output split with a beamsplitter before the OPA; ${ }^{23,63}$ and (ii) $650 \mathrm{~nm}$, taken from a portion of the OPA output that was subsequently split with a beamsplitter and frequency-doubled in a $\beta$-barium borate (BBO) crystal. $^{29}$ The time-delay between the pump and each probe pulse was scanned using independently controlled motorized translation stages (ThorLabs, Inc) on each probe beamline. The energy of each probe pulse was controlled with a variable neutral density filter. Pulse durations measured with frequencyresolved optical gating (FROG) in our previous work ${ }^{23,29}$ were $18 \mathrm{fs}$ (1300 nm pump) and $25 \mathrm{fs}$ (800 $\mathrm{nm}$ and $650 \mathrm{~nm}$ probes). The cross-correlation of pump and probe pulses, and therefore the temporal resolution of our experiment, was also measured in a previous work ${ }^{23}$ and shown to follow a Gaussian shape with FWHM of $26.1 \pm 0.2 \mathrm{fs}$, consistent with the FROG measurements. For both setups, the pump and probe pulses were recombined on dichroic mirrors and directed colinearly through a $20 \mathrm{~cm}$ fused silica biconvex lens to focus into an ultrahigh vacuum chamber (base pressure $2 \times 10^{-9}$ torr) equipped with a custom built linear 
time-of-flight mass spectrometer (TOF-MS) described in detail in our previous publications. ${ }^{63,64}$ Samples of nitrobenzene and 2-, 3-, and 4-nitrotoluene (Sigma Aldrich) were used as received and introduced into the vacuum chamber through a variable leak valve to reach working pressure in the range of $1-3 \times 10^{-7}$ torr measured at the MCP detector. Mass spectra were recorded with a $1 \mathrm{GHz}$ digital oscilloscope at a sampling rate of 20 giga samples per second (GS s${ }^{-1}$ ) (LeCroy WaveRunner 610Zi). The reported mass spectra were averaged over 10000 laser shots and transient ion signals obtained by averaging 30 pump-probe scans taken in time steps of $10 \mathrm{fs}$ with 1000 laser shots averaged at each time step. The UV-vis spectra of NB at an approximate concentration of $5 \times 10^{-5} \mathrm{M}$ in methanol and chloroform were measured using a commercial UV-vis spectrophotometer (Agilent 8453).

\section{Results}

\subsection{Computational results}

The B3LYP/Def2TZVPP optimized geometry for neutral NB shifts from a $0^{\circ} \mathrm{C}-\mathrm{C}-\mathrm{N}-\mathrm{O}$ dihedral angle to a $57.9^{\circ}$ angle for the optimized cation, this being the most dramatic geometric change between both structures (Fig. 3). In order to confirm the previous assertion, we performed a quantitative measurement of geometric change between the two structures by means of what can be called modified root-mean-square distance (MRMSD) defined as $\sqrt{\sum_{i=1}^{n} d_{l}^{2}}$ where the set of $d_{i}$ values corresponds to the minimized distances between individual atoms in both structures. Using this definition, the MRMSD is $2.62 \AA$ for oxygen atoms and $2.65 \AA$ for all the atoms meaning that most of the geometric changes when going from the neutral to the cationic structure can be accounted for by the movement of the oxygen atoms. For a full list of MRMSD values see Table S2 of the ESI. $\dagger$ Hence, motion along the $\mathrm{C}-\mathrm{NO}_{2}$ torsional coordinate is expected to dominate the nuclear dynamics of $\mathrm{NB}$ following ionization. This result also suggests that the $\mathrm{C}-\mathrm{NO}_{2}$ torsional mode may be coherently excited upon ionization to produce a vibrational wave packet in the $\mathrm{C}-\mathrm{NO}_{2}$ torsional mode. The frequency of this mode calculated using the B3LYP functional ranges from 31.8 to $67.6 \mathrm{~cm}^{-1}$, depending on the basis set used,

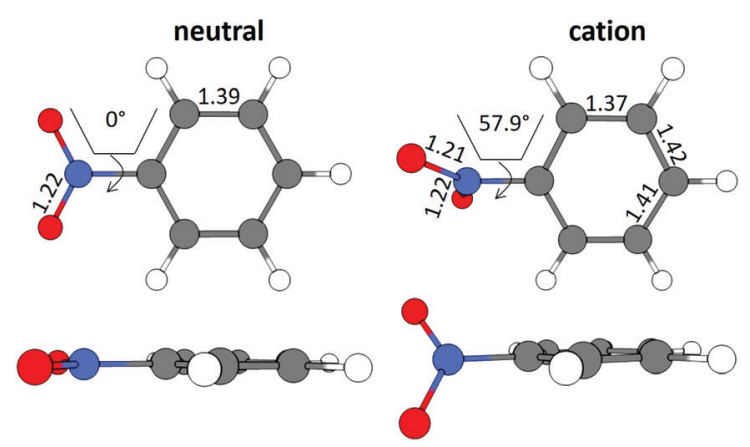

Fig. 3 Geometrical structures for neutral and cationic NB optimized at the B3LYP/Def2TZVPP level of theory. Bond lengths are in $\AA$ and torsional angles in degrees. with a value of $53.9 \mathrm{~cm}^{-1}$ for the B3LYP/Def2TZVPP level of theory (ESI, $\dagger$ Table S5). These computationally obtained values are in reasonable agreement with the experimental ion signal oscillations at $80 \mathrm{~cm}^{-1}$ (see Section 3.3). The error between computed and experimental frequencies follows in line with that found in a previous work for same torsional mode in 4-nitrotoluene cation for which computed and experimental frequencies of 46.1 and $85 \mathrm{~cm}^{-1}$ respectively were found. ${ }^{23}$

Previous femtosecond mass spectrometry measurements on NB have identified the most prominent ion signal as the $\mathrm{C}_{6} \mathrm{H}_{5}{ }^{+}$ fragment, obtained by $\mathrm{NO}_{2}$ loss from the parent $\mathrm{NB}^{+}$ion. ${ }^{42-45}$ To determine the energy needed for $\mathrm{C}_{6} \mathrm{H}_{5}{ }^{+}$generation, we performed a relaxed potential energy surface scan for the $\mathrm{C}-\mathrm{N}$ bond in $\mathrm{NB}^{+}$using the ModRedundant keyword in Gaussian at the B3LYP/Def2TZVPP level of theory (Fig. 4). The depth of the well obtained from this surface is around $1.58 \mathrm{eV}$. We estimated the zero point energy (ZPE) by adding the ZPE of the vibrational modes that heavily involve $\mathrm{C}-\mathrm{N}$ bond stretching (modes 5, 10, $12,21,25,27,29$, and 31, whose corresponding frequencies can be found in Table S5 of the ESI $\dagger$ ). The result of this estimation was $0.55 \mathrm{eV}$ (dashed black line in Fig. 4), which is reasonable since the total ZPE calculated by Gaussian, adding the ZPE for the 36 vibrational modes of NB, is $2.72 \mathrm{eV}$. Taking the ZPE into account it can be estimated that the minimum energy necessary for breaking the $\mathrm{C}_{6} \mathrm{H}_{5}-\mathrm{NO}_{2}$ bond is $1.03 \mathrm{eV}(1.58-0.55 \mathrm{eV})$, less than the energy corresponding to $800 \mathrm{~nm}$ photons $(1.55 \mathrm{eV})$ and very close to the energy of $1300 \mathrm{~nm}$ photons $(0.95 \mathrm{eV})$ as can be seen in Fig. 4 .

The ground and lowest 10 excited electronic potential energy surfaces (PESs) of NB cation along the $\mathrm{C}-\mathrm{NO}_{2}$ torsional coordinate were computed to determine potential electronic excitation pathways in NB following ionization (Fig. 5). As seen in Fig. 5a, these PESs are distributed within two groups: the first comprised by $\mathrm{D}_{0}$ to $\mathrm{D}_{4}$ and the second by $\mathrm{D}_{5}$ to $\mathrm{D}_{10}$. It is evident that the $\mathrm{D}_{2}$ through

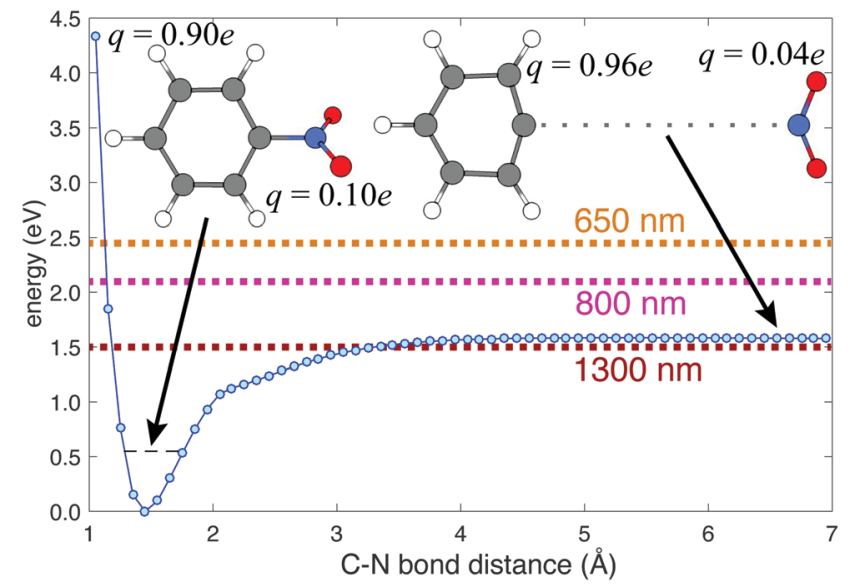

Fig. 4 Potential energy surface corresponding to the $\mathrm{C}_{6} \mathrm{H}_{5}-\mathrm{NO}_{2}$ bond stretching in NB cation calculated at the B3LYP/Def2TZVPP level of theory. Charges on each fragment are indicated at $\mathrm{C}-\mathrm{N}$ distances of $1.45 \AA$ and $6.50 \AA$. The estimation of the ZPE is shown as a dashed black line. The energies for 1300,800 , and $650 \mathrm{~nm}$ photons, relative to the ZPE, are shown as dark red, magenta, and orange dashed lines respectively. 
$\mathrm{D}_{4}$ surfaces in the first group have a marked dependence on the dihedral angle, reaching their maximum energy value at $90^{\circ}$, whereas the surfaces within the second group have a less pronounced dependence on the dihedral angle. Fig. 5a also shows the energies corresponding to 1300, 800, and $650 \mathrm{~nm}$ photons for comparison (0.95, 1.55, and $1.91 \mathrm{eV}$ respectively). Only the $650 \mathrm{~nm}$ photon energy is enough to promote the $\mathrm{D}_{0} \rightarrow \mathrm{D}_{n}, n=1, \ldots, 4$ transitions by means of single photon processes at any geometry. Moreover, $650 \mathrm{~nm}$ is nearly resonant with the $\mathrm{D}_{0} \rightarrow \mathrm{D}_{4}$ transition at a dihedral angle of $90^{\circ}$. For $800 \mathrm{~nm}$ photons, the $\mathrm{D}_{4}$ surface is out of reach from $D_{0}$ at most geometries, the $D_{3}$ surface is accessible at some geometries, and the $\mathrm{D}_{2}$ surface is reachable at any geometry. $1300 \mathrm{~nm}$ photons can only reach the $\mathrm{D}_{2}$ through $\mathrm{D}_{4}$ surfaces from $\mathrm{D}_{0}$ at dihedral angles near $0^{\circ}$, i.e., near the neutral NB geometry.

The importance of the dihedral angle for excitation probability is captured in the dependence of the oscillator strength on the dihedral angle (Fig. 5b). Some of the oscillator strengths are very close to zero for all values of the dihedral angle, but $f_{02}$, $f_{03}, f_{04}, f_{07}, f_{09}$, and $f_{010}$ have non-negligible values at different geometries. It is noteworthy that the oscillator strength for the $\mathrm{D}_{0} \rightarrow \mathrm{D}_{4}$ transition $\left(f_{04}\right)$ is particularly high and dependent on the geometry, reaching its maximum value at $90^{\circ}$. Moreover, this transition is the only one that has a substantial oscillator strength at $90^{\circ}$ (Table 2). In order to benchmark our TDDFT
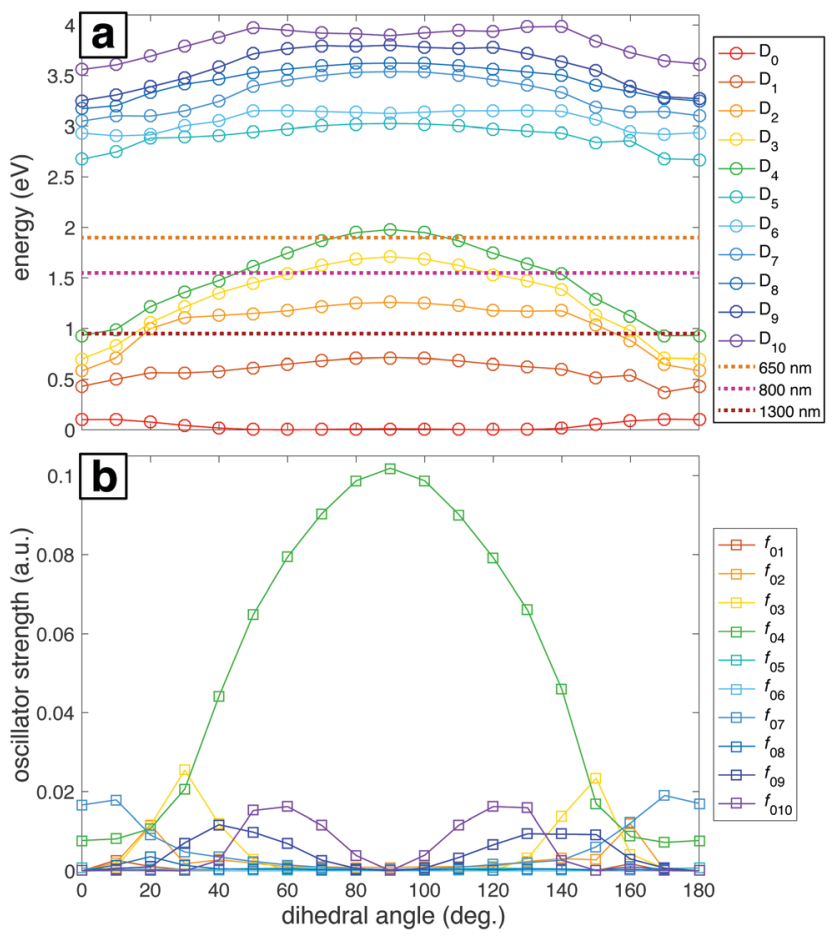

Fig. 5 (a) Potential energy surfaces for the ground ionic state $D_{0}$ and the first ten excited states $D_{1}$ through $D_{10}$ as a function of the $\mathrm{C}-\mathrm{C}-\mathrm{N}-\mathrm{O}$ dihedral angle. Energies corresponding to 1300,800 and $650 \mathrm{~nm}$ photons are shown for comparison. (b) Oscillator strengths between the ground ionic state $D_{0}$ and the excited states $D_{1}$ through $D_{10}$ as a function of the $C$ $\mathrm{C}-\mathrm{N}-\mathrm{O}$ dihedral angle. All the calculations were done at the B3LYP/ Def2TZVPP level of theory.
Table 2 Excitation energies (EE) and oscillator strengths ( $f$ ) for NB cation with $90^{\circ} \mathrm{C}-\mathrm{C}-\mathrm{N}-\mathrm{O}$ dihedral angle at the B3LYP/Def2TZVPP and EOM$\mathrm{EE}-\mathrm{CCSD} / 6-311+\mathrm{G}^{*}$ levels of theory

\begin{tabular}{llllll}
\hline & \multicolumn{2}{l}{ B3LYP/Def2TZVPP } & & \multicolumn{2}{c}{ EOM-EE-CCSD/6-311+G* } \\
\cline { 2 - 3 } Transition & EE $(\mathrm{eV})$ & $f($ a.u. $)$ & & EE $(\mathrm{eV})$ & $f($ a.u. $)$ \\
\hline $\mathrm{D}_{0} \rightarrow \mathrm{D}_{1}$ & 0.73 & 0.0000 & 0.81 & 0.0000 \\
$\mathrm{D}_{0} \rightarrow \mathrm{D}_{2}$ & 1.23 & 0.0010 & 2.00 & 0.0013 \\
$\mathrm{D}_{0} \rightarrow \mathrm{D}_{3}$ & 1.70 & 0.0000 & 2.34 & 0.1156 \\
$\mathrm{D}_{0} \rightarrow \mathrm{D}_{4}$ & 1.99 & 0.1039 & 2.49 & 0.0001 \\
$\mathrm{D}_{0} \rightarrow \mathrm{D}_{5}$ & 3.03 & 0.0000 & 3.70 & 0.0013 \\
$\mathrm{D}_{0} \rightarrow \mathrm{D}_{6}$ & 3.12 & 0.0000 & & \\
$\mathrm{D}_{0} \rightarrow \mathrm{D}_{7}$ & 3.54 & 0.0004 & & \\
$\mathrm{D}_{0} \rightarrow \mathrm{D}_{8}$ & 3.62 & 0.0002 & & \\
$\mathrm{D}_{0} \rightarrow \mathrm{D}_{9}$ & 3.80 & 0.0000 & & \\
$\mathrm{D}_{0} \rightarrow \mathrm{D}_{10}$ & 3.89 & 0.0000 & & \\
& & & &
\end{tabular}

calculations we also performed some computations using EOMEE-CCSD in combination with the $6-311+\mathrm{G}^{*}$ basis set. The geometries considered were the ones obtained after optimization at the B3LYP/Def2TZVPP level. Table 2 contains the results of these calculations for $\mathrm{NB}$ cation with $90^{\circ} \mathrm{C}-\mathrm{NO}_{2}$ torsional angle. Analogous EOM calculations for the optimized neutral and cation geometries are shown in Table S11 of ESI. $\dagger$ Comparison of results in Table 2 shows that EOM calculations confirm the presence of an excited state with a substantial oscillator strength at $90^{\circ}$ dihedral angle and with excitation energy around $2 \mathrm{eV}$, in line with the TDDFT calculations, and very importantly, with the experimental results to be discussed in the following sections. However, the ordering of the excited states is not in agreement since EOM results point to $\mathrm{D}_{3}$ as the bright state while TDDFT computations point to $\mathrm{D}_{4}$. This situation will be briefly discussed in Section 4 .

Having a substantial oscillator strength for a transition from $D_{0}$ to a specific bright state $\left(D_{3}\right.$ or $\left.D_{4}\right)$ at $90^{\circ}$ implies that, as the vibrational wave packet propagates along the $\mathrm{D}_{0}$ surface, it will have the highest probability of a one-photon excitation to the excited state surface at that particular dihedral angle. Hence, we can expect that pump-probe measurements using nearly resonant probe photons will most efficiently transfer groundstate $\mathrm{NB}^{+}$to the bright state surface at pump-probe delays corresponding to the time needed for the wave packet to reach a $90^{\circ}$ dihedral angle. To estimate this time we performed classical wave packet trajectory calculations ${ }^{21,65}$ using the $D_{0}$ surface computed in fine increments of $2^{\circ}$ (red dots, Fig. 6) and fit to a smoothing spline (solid red line, Fig. 6). The evolution of the dihedral angle of the wave packet centroid is determined by the equation of motion ${ }^{65}$

$$
\frac{\mathrm{d} \varphi}{\mathrm{d} t}=\sqrt{\frac{2}{I}[V(\varphi(0))-V(\varphi(t))+\Delta]}
$$

where $\varphi$ is the dihedral angle, $I$ is the reduced moment of inertia for the torsional motion, and $V(\varphi(t))$ is the potential energy dependent on the dihedral angle at a given time $t$ (a point of the $\mathrm{D}_{0}$ surface). The quantity $\Delta$ represents additional energy available from relaxation following vertical ionization. This equation was solved using the numerical integrator ode 45 


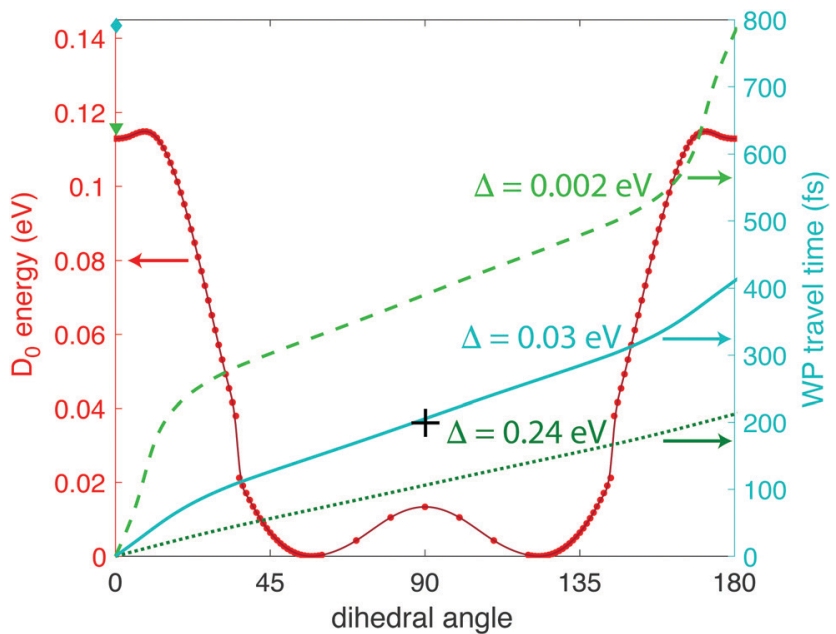

Fig. 6 Calculated wave packet trajectories over the $D_{0}$ PES (red dots and line) using 0 (bright green dashed line), 0.03 (turquoise solid line), and 0.24 $\mathrm{eV}$ (dark green dotted line) of excess energy.

in MATLAB with the computed reduced moment of inertia of $4.46 \times 10^{-46} \mathrm{~kg} \mathrm{~m}^{2}$.

From Fig. 6 we can see a local minimum in the $\mathrm{D}_{0}$ surface at $0^{\circ}$ dihedral angle; if we consider this surface as periodic, that local minimum constitutes a potential well. Hence, the wave packet will need at least $\Delta \geq 0.002 \mathrm{eV}$ excess energy to surpass the barrier at $\sim 9^{\circ}$ dihedral angle. It is reasonable to assume that the source of that energy is some fraction of the excess energy after ionization, i.e., the difference between vertical and adiabatic ionization energies. At the B3LYP/Def2TZVPP level, this excess energy is $0.35 \mathrm{eV}$ (Table 1), giving an upper limit of $\Delta=0.24 \mathrm{eV}$ in eqn (1). Fig. 6 shows the wave packet trajectories along the $\mathrm{D}_{0}$ PES (red line) obtained with $\Delta=0.002 \mathrm{eV}$ (light green dashed line), $\Delta=0.03 \mathrm{eV}$ (turquoise solid line), and $\Delta=$ $0.24 \mathrm{eV}$ (dark green dotted line). As expected, the time taken for the wave packet to reach a $90^{\circ}$ dihedral angle changes with the value of $\Delta$, with times around 400, 200, and $100 \mathrm{fs}$ for $\Delta=0$, 0.03 , and $0.24 \mathrm{eV}$, respectively. As will be shown in Section 3.2 below, the pump-probe measurements indicate that the wave packet reaches the $90^{\circ}$ torsional angle in $\sim 200 \mathrm{fs}$, suggesting a physically plausible value of $\Delta=0.03 \mathrm{eV}$, or $9 \%$ of the available relaxation energy, to "kick-start" the wave packet.

\subsection{Pump-probe measurements}

Fig. 7a shows the mass spectra of NB taken with $7 \times 10^{13} \mathrm{~W} \mathrm{~cm}^{-2}$, $1300 \mathrm{~nm}$ pump pulses and $1 \times 10^{13} \mathrm{~W} \mathrm{~cm}^{-2}$ probe pulses at $800 \mathrm{~nm}$ and $650 \mathrm{~nm}$, with the delay $\tau$ between pump and probe pulses set to $4 \mathrm{ps}$. The bottom spectrum (dark red) obtained using only the $1300 \mathrm{~nm}$ ionizing pump pulse exhibits significant yields of parent molecular ion $\mathrm{NB}^{+}(\mathrm{m} / \mathrm{z} 123)$ and $\mathrm{C}_{6} \mathrm{H}_{5}{ }^{+}(\mathrm{m} / \mathrm{z} 77)$ with little additional fragmentation. Notably, the similar intensity of the parent $\mathrm{NB}^{+}$and $\mathrm{C}_{6} \mathrm{H}_{5}^{+}$peaks stands in stark contrast to earlier measurements on NB using $800 \mathrm{~nm}$ fs excitation for ionization, where the $\mathrm{C}_{6} \mathrm{H}_{5}{ }^{+}$signal was at least an order of magnitude more intense than the $\mathrm{NB}^{+}$signal. ${ }^{42-44}$ This result is expected on the basis of the computed PES along the $\mathrm{C}-\mathrm{N}$ bond coordinate (Fig. 4),

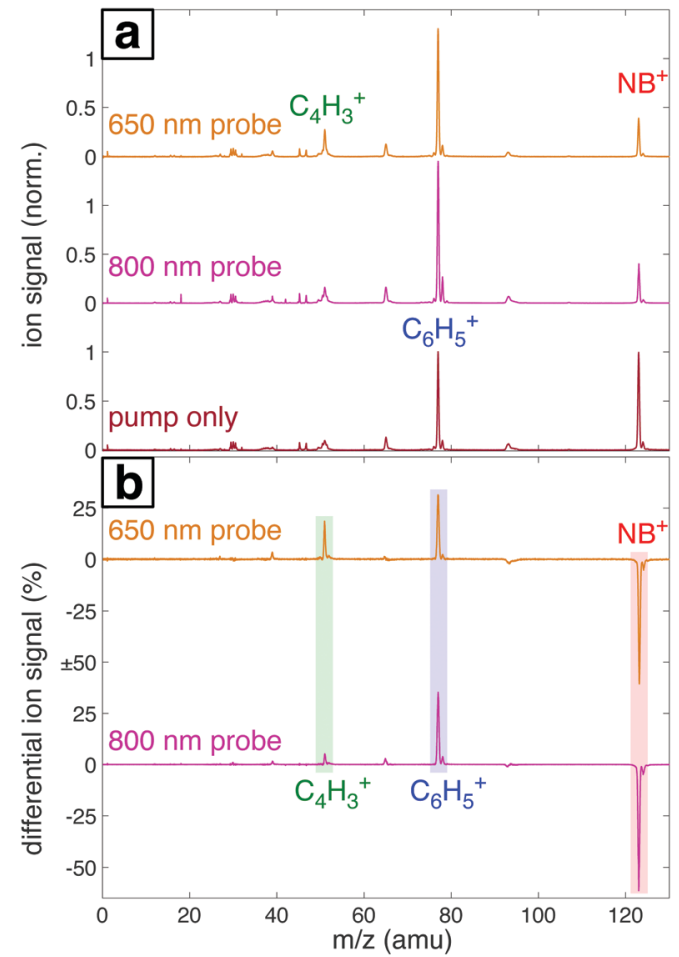

Fig. 7 (a) Mass spectra of NB taken with $1300 \mathrm{~nm}$ pump only (dark red, bottom), $800 \mathrm{~nm}$ probe (magenta, middle), and $650 \mathrm{~nm}$ probe (orange, top) at 4 ps delay. (b) Difference mass spectra between the $800 \mathrm{~nm}$ and $650 \mathrm{~nm}$ probe spectra and pump-only spectrum in (a). The signals for parent ion $\mathrm{NB}^{+}$(red), $\mathrm{C}_{6} \mathrm{H}_{5}{ }^{+}$(blue), and $\mathrm{C}_{4} \mathrm{H}_{3}{ }^{+}$(green) are highlighted.

which shows that $800 \mathrm{~nm}$ photons substantially exceed the energy needed for $\mathrm{NO}_{2}$ loss, whereas $1300 \mathrm{~nm}$ photons barely provide sufficient energy. When an $800 \mathrm{~nm}$ (middle spectrum, magenta) or $650 \mathrm{~nm}$ (top spectrum, orange) probe pulse is present at a $4 \mathrm{ps}$ delay, the relative yield of the parent $\mathrm{NB}^{+}$ion decreases by $\sim 60 \%$, while the yields of the $\mathrm{C}_{6} \mathrm{H}_{5}{ }^{+}$and $\mathrm{C}_{4} \mathrm{H}_{3}{ }^{+}$(m/z 51) fragments increase. These changes are further magnified in the difference spectra shown in Fig. 7b. Whereas parent depletion and $\mathrm{C}_{6} \mathrm{H}_{5}{ }^{+}$ enhancement are similar for both $800 \mathrm{~nm}$ and $650 \mathrm{~nm}$ probe photons, the enhancement of $\mathrm{C}_{4} \mathrm{H}_{3}{ }^{+}$is significantly higher using $650 \mathrm{~nm}$ photons. While the $\mathrm{C}_{6} \mathrm{H}_{5}{ }^{+}$fragment is clearly the $\mathrm{NO}_{2}$ loss product from the parent ion, the origin of the $\mathrm{C}_{4} \mathrm{H}_{3}{ }^{+}$ fragment has not been completely elucidated. Threshold photoelectron-photoion coincidence (TPEPICO) spectroscopy experiments suggest that the $\mathrm{C}_{4} \mathrm{H}_{3}{ }^{+}$fragment can be formed from secondary dissociation of $\mathrm{C}_{6} \mathrm{H}_{5}{ }^{+} .{ }^{6}$

Fig. 8 shows the transient signals of the ions highlighted in Fig. 7 as a function of pump-probe delay $(\tau)$ using $800 \mathrm{~nm}$ (a) and $650 \mathrm{~nm}$ (b) probe pulses at intensities $10^{13} \mathrm{~W} \mathrm{~cm}^{-2}$ (top) and $10^{12} \mathrm{~W} \mathrm{~cm}^{-2}$ (bottom). All transients are normalized to the yield of $\mathrm{NB}^{+}$at $\tau<0$. Depletion in $\mathrm{NB}^{+}$(red) and increase in $\mathrm{C}_{6} \mathrm{H}_{5}{ }^{+}$(blue) signals at $\tau>0$ are observed under all conditions, with greater magnitude changes for high probe intensity (top panels) due to increased excitation probability. The yield of $\mathrm{C}_{4} \mathrm{H}_{3}{ }^{+}$increases significantly for $\tau>0$ only at $10^{13} \mathrm{~W} \mathrm{~cm}^{-2}$, with greater enhancement for the $650 \mathrm{~nm}$ wavelength. The antiphase oscillations in the yields of $\mathrm{NB}^{+}$and $\mathrm{C}_{6} \mathrm{H}_{5}{ }^{+}$(inset in each panel of Fig. 8), with similar 
frequency to related aromatic molecules, ${ }^{19-23,29}$ indicate that electronic excitation of the $\mathrm{NB}^{+}$vibrational wave packet along the C- $\mathrm{NO}_{2}$ torsional mode (Fig. 3 and 5) results in $\mathrm{C}_{6} \mathrm{H}_{5}{ }^{+}$formation. The greater oscillation amplitude using the $650 \mathrm{~nm}$ wavelength, particularly at lower intensity (bottom panels), is consistent with the prediction based on the computed PESs in Fig. 5 that $650 \mathrm{~nm}$ photons are more efficient at exciting the $\mathrm{NB}^{+}$ vibrational wave packet.

\subsection{Quantitative analysis of oscillatory dynamics}

To quantify the enhancement of oscillation amplitudes observed in the transient signals in Fig. 8 using the $650 \mathrm{~nm}$ probe wavelength, nonlinear least squares curve fitting ${ }^{21-26,29}$ was applied to the signals. The fit equation used for the transient ion signals in Fig. 8 is

$$
S(\tau)=a \mathrm{e}^{-\tau / T_{1}} \cos \left(\frac{2 \pi}{t} \tau+\phi\right)+b \mathrm{e}^{-\tau / T_{2}}+c \mathrm{e}^{-\tau / T_{3}}+d
$$

where $a, b$, and $c$ are amplitude coefficients, $t$ is the oscillation period, $T_{1}$ is the coherence lifetime, $T_{2}$ and $T_{3}$ are incoherent lifetimes (i.e., not associated with oscillations), and $d$ is the ion yield as $\tau \rightarrow \infty$. Each transient signal at $\tau \geq 70$ fs (i.e., after the pump pulse is over so the instrument response function can be ignored) was fit to eqn (2) using nonlinear least-squares curve fitting in MATLAB, as illustrated in the ESI, $\dagger$ Fig. S4.

Under all conditions, the parent $\mathrm{NB}^{+}$ion was fit to the complete eqn (2), $\mathrm{C}_{6} \mathrm{H}_{5}{ }^{+}$fit to eqn (2) without the $T_{3}$ component, and $\mathrm{C}_{4} \mathrm{H}_{3}{ }^{+}$fit to the complete eqn (2) for $650 \mathrm{~nm}$ excitation at $10^{13} \mathrm{~W} \mathrm{~cm}^{-2}$ or without the oscillatory $T_{1}$ component otherwise (ESI, $\dagger$ Tables S12-S15). To compare the oscillatory dynamics observed under the four experimental conditions in Fig. 8, the tabulated $a, T_{1}, t$, and $\phi$ coefficients for the parent $\mathrm{NB}^{+}$ion extracted from curve fitting are reported in Table 3. For all four conditions, the coherence lifetime $T_{1}$, oscillation period $t$, and
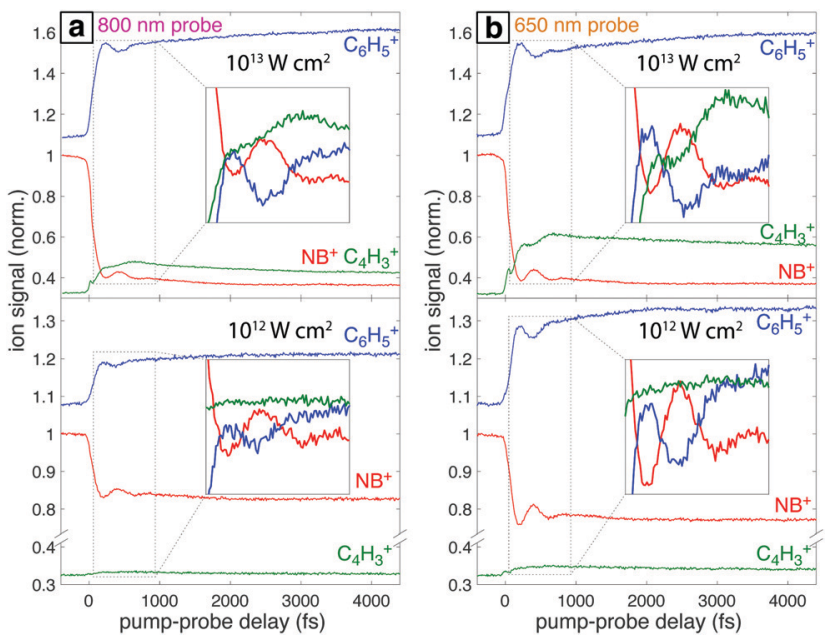

Fig. 8 Transient ion signals from $\mathrm{NB}^{+}$obtained with (a) $800 \mathrm{~nm}$ and (b) $650 \mathrm{~nm}$ probe pulses. Probe intensity is $10^{13} \mathrm{~W} \mathrm{~cm}^{-2}$ (top panels) and $10^{12}$ $\mathrm{W} \mathrm{cm} \mathrm{cm}^{-2}$ (bottom panels). Insets magnify the 70-830 fs range to show the oscillations, curves within the inset have been shifted vertically to show oscillatory behavior more clearly.
Table 3 Coefficients for $\mathrm{NB}^{+}$transients fit to eqn (2). I: probe intensity in $\mathrm{W} \mathrm{cm}^{-2}$

\begin{tabular}{lllll}
\hline Eqn $(2)$ & $a$ & $T_{1}(\mathrm{fs})$ & $t(\mathrm{fs})$ & $\phi(\mathrm{rad})$ \\
\hline $650 \mathrm{~nm}, I=10^{13}$ & $0.14 \pm 0.02$ & $239 \pm 15$ & $430 \pm 9$ & $-0.08 \pm 0.09$ \\
$650 \mathrm{~nm}, I=10^{12}$ & $0.11 \pm 0.02$ & $242 \pm 15$ & $426 \pm 10$ & $-0.04 \pm 0.08$ \\
$800 \mathrm{~nm}, I=10^{13}$ & $0.08 \pm 0.01$ & $244 \pm 24$ & $439 \pm 15$ & $-0.13 \pm 0.19$ \\
$800 \mathrm{~nm}, I=10^{12}$ & $0.05 \pm 0.01$ & $225 \pm 41$ & $426 \pm 10$ & $-0.05 \pm 0.21$
\end{tabular}

phase $\phi$ agree to within the reported errors (95\% confidence intervals from curve fitting). This result confirms that the same initial wave packet was prepared by the ionizing pump pulse because the parameters $T_{1}, t$, and $\phi$ are intrinsic to the wave packet dynamics. In contrast, the $a$ coefficients associated with the oscillation amplitude are greater for $650 \mathrm{~nm}$ as compared to $800 \mathrm{~nm}$ excitation: the $a$ value of $0.11 \pm 0.02$ obtained with $650 \mathrm{~nm}$ is twice the $0.05 \pm 0.01$ value obtained with $800 \mathrm{~nm}$ at the modest intensity of $10^{12} \mathrm{~W} \mathrm{~cm} \mathrm{~cm}^{-2}$. This result is consistent with the more prominent oscillations visible in Fig. $8 \mathrm{~b}$ as compared to Fig. 8a. Greater values of a coefficients for the $\mathrm{C}_{6} \mathrm{H}_{5}{ }^{+}$fragment are also observed with $650 \mathrm{~nm}$ probe as compared to $800 \mathrm{~nm}$ probe (ESI, $\dagger$ Tables S12-S15).

To further illustrate the enhancement of the oscillatory ion signals using $650 \mathrm{~nm}$ excitation, the residual oscillatory ion signals obtained after subtraction of the incoherent components ( $T_{2}$ and $T_{3}$ terms) from eqn (2) are plotted in Fig. 9, left panel. This plot clearly shows the antiphase behavior of the oscillations in $\mathrm{NB}^{+}$(red) and $\mathrm{C}_{6} \mathrm{H}_{5}{ }^{+}$(blue), as indicated by the dotted lines at the minima of $\mathrm{NB}^{+}$yield ( 200 and $630 \mathrm{fs}$ ). For $650 \mathrm{~nm}$ excitation at $10^{13} \mathrm{~W} \mathrm{~cm}{ }^{-2}$, the $\mathrm{C}_{4} \mathrm{H}_{3}{ }^{+}$(green) fragment also exhibits antiphase oscillations with respect to $\mathrm{NB}^{+}$. At both intensities, the larger-amplitude oscillations using $650 \mathrm{~nm}$ are apparent in the increased amplitude of the corresponding Fast Fourier Transform (FFT) peak at $80 \mathrm{~cm}^{-1}$ (dashed line) taken from the residual ion signals over the pump-probe delay range of 70-3000 fs (Fig. 9, right panel). In particular, the $80 \mathrm{~cm}^{-1}$ peak intensity for $\mathrm{NB}^{+}$at $10^{12} \mathrm{~W} \mathrm{~cm} \mathrm{~cm}^{-2}$ is approximately five times higher for $650 \mathrm{~nm}$ as compared to $800 \mathrm{~nm}$ excitation. Hence, quantification of the oscillations indicate an amplitude enhancement by a factor of $\sim 2-5$ using $650 \mathrm{~nm}$ for excitation as compared to $800 \mathrm{~nm}$, consistent with the theoretical predictions from Fig. 5 .

\subsection{Comparison of nitrobenzene and nitrotoluenes}

In order to further explore the effect of the probe excitation wavelength in the study of radical cation dynamics, we briefly discuss the occurrence of analogous behaviors in the closely related nitrotoluenes (NTs). Fig. 10 shows the transient ion signals for the parent ions $\mathrm{M}^{+}$and the $\mathrm{NO}_{2}$ loss products for 4-NT, 3-NT, and 2-NT as well as nitrobenzene for comparison. Measurements were taken with $7 \times 10^{13} \mathrm{~W} \mathrm{~cm}^{-2}, 1300 \mathrm{~nm}$ pump pulses and $1 \times 10^{12} \mathrm{~W} \mathrm{~cm}^{-2}$ probe pulses at $800 \mathrm{~nm}$ and $650 \mathrm{~nm}$ for all the molecules except for 3-NT, for which probe pulses of $6 \times 10^{12} \mathrm{~W} \mathrm{~cm}^{-2}$ were used. Among these four molecules, NB stands out in that the $\left[\mathrm{M}-\mathrm{NO}_{2}\right]^{+}$fragment has a higher yield than the parent ion $\mathrm{M}^{+}$at negative delay, which is attributed to NB having the lowest $\mathrm{C}-\mathrm{N}$ bond dissociation 

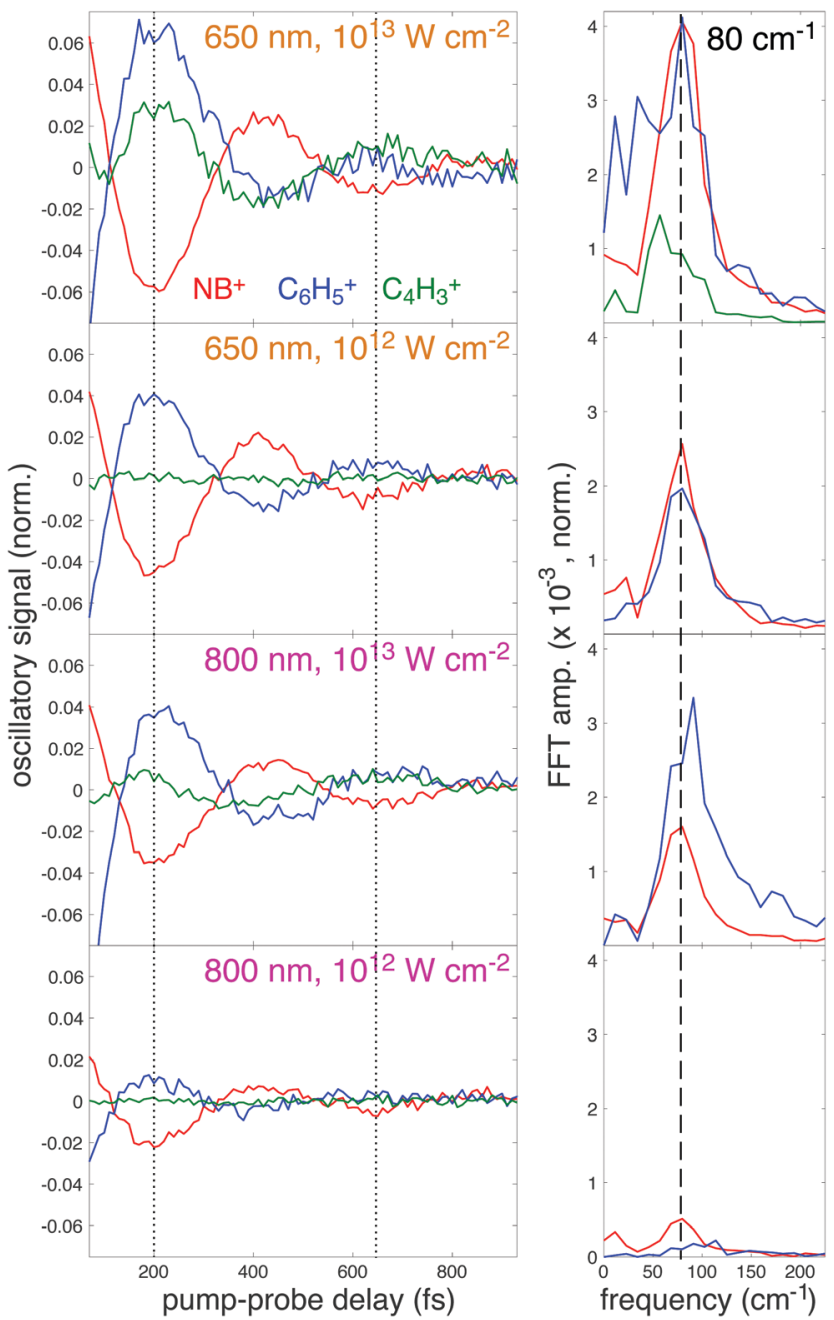

Fig. 9 Residual ion signals (left) and FFT power spectra (right).

energy (BDE) as indicated in Fig. 10. Although the BDE in 2-NT is similar (1.56 eV in NB vs. $1.58 \mathrm{eV}$ in 2-NT), the 2-NT can undergo additional fragmentation pathways that compete with $\mathrm{C}-\mathrm{N}$ cleavage ${ }^{29}$ as shown in the mass spectra in the ESI, $\dagger$ Fig. S5. Nevertheless, all these systems with the exception of 3-NT show a similar enhancement of the oscillatory dynamics with $650 \mathrm{~nm}$ excitation as compared with $800 \mathrm{~nm}$. We note that the lack of enhanced $\left[\mathrm{M}-\mathrm{NO}_{2}\right]^{+}$yield in 2-NT can also be attributed to competition with other fragmentation pathways. Our previous finding that the optimized 2-NT cation has an excited state nearly resonant with $650 \mathrm{~nm}$ using TDDFT calculations at the $\omega B$ 97XD/CBSB7 and CAM-B3LYP/CBSB7 levels ${ }^{29}$ further supports the main hypothesis explored in this work that computations can predict the best excitation wavelength. On the basis of these results, we can predict the existence of a resonant transition at $650 \mathrm{~nm}$ for 4-NT and the absence of such a resonance for 3-NT, which may be expected because 3-NT does not undergo torsional wave packet motion upon ionization. ${ }^{23}$ We note that the common behavior of NB, 2-NT, and 4-NT cations with regards to torsional wave packet motion and accessible electronic transitions is similar to previous studies of acetophenone $\mathrm{e}^{21,22}$ and its methyl-substituted
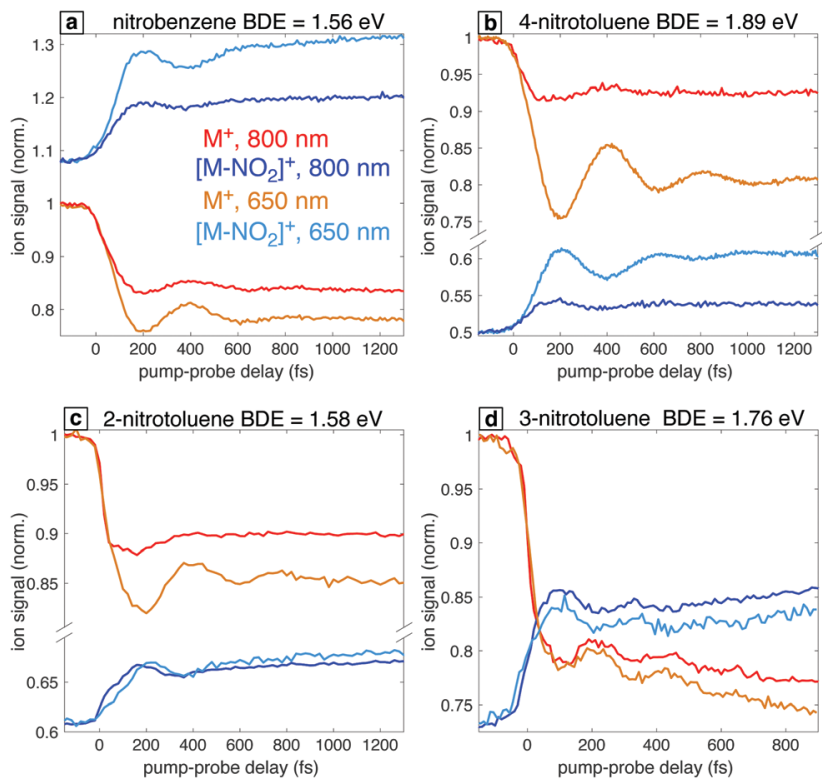

Fig. 10 Transient ion signals of parent ions $\mathrm{M}^{+}$(red and orange) and [M$\left.\mathrm{NO}_{2}\right]^{+}$(dark and light blue) for NB (a), 4-NT (b), 2-NT (c), and 3-NT (d). Bond dissociation energies (BDE) of the $\mathrm{C}-\mathrm{N}$ bond calculated the B3LYP/Def2TZVPP level for these four radical cations are also shown.

derivatives: ${ }^{19,20}$ acetophenone, 2-methylacetophenone, and 4-methylacetophenone undergo torsional wave packet motion that can be excited with an $800 \mathrm{~nm}$ probe, whereas 3-methylacetophenone does not.

\section{Discussion}

It is common practice in time-resolved studies of radical cations to probe with the readily available $800 \mathrm{~nm}$ wavelength. ${ }^{16-27}$ In this work we want to address whether theoretical computations can predict a more suitable wavelength for probing vibrational wave packet dynamics in radical cations. Indeed, the enhancement of wave packet oscillation amplitudes in NB cation at modest probe pulse intensity $\left(10^{12} \mathrm{~W} \mathrm{~cm}^{-2}\right)$ using $650 \mathrm{~nm}$ as compared to $800 \mathrm{~nm}$ for excitation validates the computational results showing a geometry-dependent excitation probability from the $\mathrm{D}_{0}$ to $\mathrm{D}_{4}$ surface and resonance of the $650 \mathrm{~nm}$ excitation wavelength. These results will be further discussed in this section.

Both the 650 and $800 \mathrm{~nm}$ excitation wavelengths are capable of increasing the $\mathrm{C}_{6} \mathrm{H}_{5}{ }^{+}$signal at the expense of the parent ion signal (Fig. 7), even though only the $650 \mathrm{~nm}$ probe is capable of promoting the $\mathrm{D}_{0} \rightarrow \mathrm{D}_{4}$ transition for any geometry according to our TDDFT calculations (Fig. 5a). This result is consistent with previous mass spectrometry studies using only one $800 \mathrm{~nm}$ pulse for ionization that show substantial $\mathrm{C}_{6} \mathrm{H}_{5}{ }^{+}$ion signal and little parent ion, ${ }^{42-44}$ and suggests that ionization of $\mathrm{NB}$ at $800 \mathrm{~nm}$ can populate one or more electronic excited states of the cation. Because the $800 \mathrm{~nm}$ wavelength can access the $\mathrm{D}_{2}$ excited state at all geometries, excitation to $\mathrm{D}_{2}$ is likely sufficient to produce $\mathrm{NO}_{2}$ loss, at least at geometries where its energy is above the estimated dissociation threshold of $1.03 \mathrm{eV}$ (Fig. 4). We cannot rule out the contribution of the $\mathrm{D}_{3}$ excited 
state to the dissociative event because $800 \mathrm{~nm}$ excitation is also able to promote the $D_{0} \rightarrow D_{3}$ transition for some geometries. The participation of the $D_{0} \rightarrow D_{1}$ transition can be excluded due to the negligible values of $f_{01}$ (Fig. 5b) and more importantly because the energy of the $\mathrm{D}_{1}$ excited state at any geometry lies below the minimum energy to break the $\mathrm{C}-\mathrm{N}$ bond. Hence, the key difference between $800 \mathrm{~nm}$ and $650 \mathrm{~nm}$ excitation is that only $650 \mathrm{~nm}$ gives full accessibility to the $\mathrm{D}_{4}$ surface, for which the coupling strength to $\mathrm{D}_{0}$ has a strong geometric dependence. This circumstance explains the enhanced oscillatory behavior for $650 \mathrm{~nm}$ excitation (Fig. 8 and 9).

The observation that the $650 \mathrm{~nm}$ excitation is more efficient at generating the $\mathrm{C}_{4} \mathrm{H}_{3}{ }^{+}$fragment as compared to the $800 \mathrm{~nm}$ excitation (Fig. 7b) suggests that the excited state(s) involved should be at the reach of the $650 \mathrm{~nm}$ wavelength to a greater extent than for $800 \mathrm{~nm}$. In addition, the finding of substantially enhanced $\mathrm{C}_{4} \mathrm{H}_{3}{ }^{+}$yield at high probe intensity $\left(10^{13} \mathrm{~W} \mathrm{~cm}^{-2}\right.$, top panels of Fig. 8) as compared to modest probe intensity $\left(10^{12} \mathrm{~W} \mathrm{~cm}^{-2}\right.$, bottom panels of Fig. 8) supports the idea that the excited state(s) responsible for $\mathrm{C}_{4} \mathrm{H}_{3}{ }^{+}$formation can only be reached by means of a two-photon process. These facts suggest that the two photon process(es) involved in the $\mathrm{C}_{4} \mathrm{H}_{3}{ }^{+}$fragment production are more efficient for the $650 \mathrm{~nm}$ probe as compared to the $800 \mathrm{~nm}$. Moreover, we can postulate the existence of a two-photon resonant process achievable only with the $650 \mathrm{~nm}$ excitation. After eliminating the incoherent part from the $\mathrm{C}_{4} \mathrm{H}_{3}{ }^{+}$transient, the oscillatory nature of the transient is only observed with $650 \mathrm{~nm}$ probe, whereas the transient for the $800 \mathrm{~nm}$ probe only shows a feeble oscillatory behavior (Fig. 9). Because the $\mathrm{D}_{5}$ and $\mathrm{D}_{6}$ PESs do not depend on the dihedral angle while the $D_{7}$ to $D_{10}$ PESs show a modest dependence (Fig. 5a), we can postulate that the excited state(s) involved in the two photon process generating $\mathrm{C}_{4} \mathrm{H}_{3}{ }^{+}$lie(s) between $\mathrm{D}_{7}$ and $\mathrm{D}_{10}$. These states span an excitation energy range from 3.54 to $3.89 \mathrm{eV}$ (Table 2), which can be reached with two $650 \mathrm{~nm}$ photons $(3.82 \mathrm{eV})$. The dependence on geometry for the $\mathrm{D}_{7}$ to $\mathrm{D}_{10}$ PESs could be associated with the oscillatory behavior observed for the $650 \mathrm{~nm}$ probe. On the other hand, the energy corresponding to two $800 \mathrm{~nm}$ photons $(3.10 \mathrm{eV})$ cannot reach the $\mathrm{D}_{7}$ and higher states. As a last observation we want to point out that the residual ion signal for $\mathrm{C}_{4} \mathrm{H}_{3}{ }^{+}$shows antiphase coupling between $\mathrm{NB}^{+}$and $\mathrm{C}_{4} \mathrm{H}_{3}{ }^{+}$(Fig. 9), suggesting that the $\mathrm{C}_{4} \mathrm{H}_{3}{ }^{+}$fragment originates from the $\mathrm{D}_{0}$ surface of the parent ion. This result suggests that two-photon excitation of $\mathrm{NB}^{+}$ provides sufficient energy to further fragment initially formed $\mathrm{C}_{6} \mathrm{H}_{5}{ }^{+}$into $\mathrm{C}_{4} \mathrm{H}_{3}{ }^{+}$, as observed in TPEPICO studies. ${ }^{66}$

Collectively, the results of this work both illustrate how quantum chemical computations can predict the outcome of pump-probe measurements on radical cations and highlight similarities in the observed dynamics, and thereby the similar electronic structures, of homologous radical cations. Hence, this work builds on previous studies wherein computed electronic PESs of cations including bromoiodomethane, ${ }^{17,18}$ acetophenone, ${ }^{21,22}$ and azobenzene ${ }^{27}$ are used to explain transient oscillatory dynamics of ion signals observed in pump-probe measurements. Moreover, this work demonstrates that computations of electronic
PESs, even using the inexpensive TDDFT method, provide sufficiently accurate results to predict the best probe excitation wavelength in pump-probe measurements of nitrobenzene and closely related nitroaromatic compounds to maximize the visibility of vibrational wave packet dynamics. However, as the comparison of TDDFT and EOM results in Table 2 showed, our inexpensive TDDFT approach is not free of problems: TDDFT appears to misidentify the bright state as $\mathrm{D}_{4}$ instead of $\mathrm{D}_{3}$ and predicts excitation energy lower by $0.35 \mathrm{eV}$. Previous works have pointed out deficiencies on the TDDFT description of low-lying singlet excited states of various classes of molecules including polyacenes, ${ }^{67,68}$ thiophene and short thienoacenes, ${ }^{69}$ fused heteroaromatic rings, ${ }^{70}$ and naphthol isomers. ${ }^{71}$ Further work should be carried out to fully elucidate the nature of the excited states of related nitroaromatic radical cations and to rationalize and possibly mitigate the drawbacks of their TDDFT description. It is important to emphasize that any extension of this TDDFT approach to different groups of molecules should be carefully evaluated with the aid of higher level methodologies.

Additionally, our results complement previous studies showing that selection of near-infrared wavelengths for the ionizing pump also enhances the visibility of oscillatory ion dynamics by more selectively populating the ground electronic state of the cation. ${ }^{21,25}$ Finally, our results provide further evidence that similar coherent vibrational dynamics in radical cations are to be expected for families of homologous molecules. ${ }^{17,20,26}$ In particular, the ortho/ para directing nature of the nitro group is confirmed in our pumpprobe measurements due to the completely different dynamics of 3-NT as compared to NB, 2-NT, and 4-NT (Fig. 10).

\section{Conclusions}

We have demonstrated that TDDFT computations of electronic potential energy surfaces in the nitrobenzene radical cation can be used to predict the best choice of the probe wavelength in femtosecond time-resolved mass spectrometry measurements. EOMCCSD computations confirmed that a strongly coupled electronic transition out of $D_{0}$ is both resonant with $650 \mathrm{~nm}$ excitation and has a geometry-dependent oscillator strength, with strongest coupling at a $\mathrm{C}-\mathrm{C}-\mathrm{N}-\mathrm{O}$ dihedral angle of $90^{\circ}$. This result predicted the substantial enhancement by a factor of $\sim 2-5$ in the ion yield oscillations observed in nitrobenzene cation as a function of pump-probe delay. The analogous behavior observed in the related molecules 2- and 4-nitrotoluene highlights that similar vibrational dynamics are to be expected in pump-probe measurements on homologous molecules. Collectively, our results point to the importance of rationally selecting the probe wavelength for time-resolved measurements of prepared vibrational coherent states on the basis of theoretical results. This knowledge can benefit design of coherent control schemes and quantum information applications.

\section{Conflicts of interest}

There are no conflicts to declare. 


\section{Acknowledgements}

The authors acknowledge the support of the U.S. Army Research Office through Contract W911NF-19-1-0099. DAB acknowledges generous financial support from an Altria Graduate Research Fellowship. High Performance Computing resources provided by the High Performance Research Computing (HPRC) Core Facility at Virginia Commonwealth University (https://chipc.vcu. edu) were used for conducting portions of the research reported in this work.

\section{References}

1 E. J. Reed, J. Phys. Chem. C, 2012, 116, 2205-2211.

2 M. D. Sevilla, D. Becker, A. Kumar and A. Adhikary, Radiat. Phys. Chem., 2016, 128, 60-74.

3 T. P. Snow, V. Le Page, Y. Keheyan and V. M. Bierbaum, Nature, 1998, 391, 259-260.

4 K. Ledingham and R. Singhal, Int. J. Mass Spectrom. Ion Processes, 1997, 163, 149-168.

5 M. Lezius, V. Blanchet, D. M. Rayner, D. M. Villeneuve, A. Stolow and M. Y. Ivanov, Phys. Rev. Lett., 2001, 86, 51-54.

6 M. Lezius, V. Blanchet, M. Y. Ivanov and A. Stolow, J. Chem. Phys., 2002, 117, 1575-1588.

7 T. Yatsuhashi and N. Nakashima, J. Phys. Chem. A, 2005, 109, 9414-9418.

8 T. Bohinski, K. M. Tibbetts, M. Tarazkar, D. Romanov, S. Matsika and R. J. Levis, J. Phys. Chem. Lett., 2013, 4, 1587-1591.

9 T. Bohinski, K. M. Tibbetts, M. Tarazkar, D. Romanov, S. Matsika and R. Levis, J. Phys. Chem. A, 2013, 117, 12374-12381.

10 T. Bohinski, K. M. Tibbetts, K. Munkerup, M. Tarazkar, D. A. Romanov, S. Matsika and R. J. Levis, Chem. Phys., 2014, 442, 81-85.

11 K. M. Tibbetts, T. Bohinski, K. Munkerup, M. Tarazkar and R. Levis, J. Phys. Chem. A, 2014, 118, 8170-8176.

12 R. Itakura, J. Watanabe, A. Hishikawa and K. Yamanouchi, J. Chem. Phys., 2001, 114, 5598-5606.

13 H. Harada, S. Shimizu, T. Yatsuhashi, S. Sakabe, Y. Izawa and N. Nakashima, Chem. Phys. Lett., 2001, 342, 563-570.

14 S. A. Trushin, W. Fuß and W. E. Schmid, J. Phys. B: At. Opt. Mol. Phys., 2004, 37, 3987-4011.

15 D. Wu, Q. Wang, X. Cheng, M. Jin, X. Li, Z. Hu and D. Ding, J. Phys. Chem. A, 2007, 111, 9494-9498.

16 B. Pearson, S. Nichols and T. Weinacht, J. Chem. Phys., 2007, 127, 131101.

17 S. Nichols, T. Weinacht, T. Rozgonyi and B. Pearson, Phys. Rev. A: At., Mol., Opt. Phys., 2009, 79, 043407.

18 J. Gonzalez-Vazquez, L. Gonzalez, S. R. Nichols, T. C. Weinacht and T. Rozgonyi, Phys. Chem. Chem. Phys., 2010, 12, 14203-14216.

19 X. Zhu, V. V. Lozovoy, J. D. Shah and M. Dantus, J. Phys. Chem. A, 2011, 115, 1305-1312.

20 A. Konar, Y. Shu, V. V. Lozovoy, J. E. Jackson, B. G. Levine and M. Dantus, J. Phys. Chem. A, 2014, 118, 11433-11450.

21 T. Bohinski, K. M. Tibbetts, M. Tarazkar, D. A. Romanov, S. Matsika and R. J. Levis, J. Phys. Chem. Lett., 2014, 5, 4305-4309.
22 K. M. Tibbetts, M. Tarazkar, T. Bohinski, D. A. Romanov, S. Matsika and R. J. Levis, J. Phys. B: At. Opt. Mol. Phys., 2015, 48, 164002.

23 D. Ampadu Boateng, G. L. Gutsev, P. Jena and K. M. Tibbetts, J. Chem. Phys., 2018, 148, 134305.

24 K. M. Tibbetts, Chem. - Eur. J., 2019, 25, 8431-8439.

25 D. Ampadu Boateng, G. L. Gutsev, P. Jena and K. M. Tibbetts, Phys. Chem. Chem. Phys., 2018, 20, 4636-4640.

26 D. Ampadu Boateng, M. D. Word and K. M. Tibbetts, Molecules, 2019, 24, 509.

27 K. Munkerup, D. Romanov, T. Bohinski, A. B. Stephansen, R. J. Levis and T. I. Sølling, J. Phys. Chem. A, 2017, 121, 8642-8651.

28 J.-W. Ho, W.-K. Chen and P.-Y. Cheng, J. Chem. Phys., 2009, 131, 134308.

29 D. Ampadu Boateng, M. D. Word, L. G. Gutsev, P. Jena and K. M. Tibbetts, J. Phys. Chem. A, 2019, 123, 1140-1152.

30 R. Y. Brogaard, K. B. Møller and T. I. Sølling, J. Phys. Chem. A, 2011, 115, 12120-12125.

31 W. Zuo, H. Yin, X. Liu, H. Lv, L. Zhao, Y. Shi, B. Yan, M. Jin, D. Ding and H. Xu, Chem. Phys. Lett., 2016, 654, 18-22.

32 L. Zhou, Y. Liu, T. Sun, S. Feng, H. Lv and H. Xu, J. Phys. Chem. A, 2019, 123, 8365-8369.

33 C.-C. Shen, T.-T. Tsai, J.-W. Ho, Y.-W. Chen and P.-Y. Cheng, J. Chem. Phys., 2014, 141, 171103.

34 C.-C. Shen, T.-T. Tsai, J.-Y. Wu, J.-W. Ho, Y.-W. Chen and P.-Y. Cheng, J. Chem. Phys., 2017, 147, 164302.

35 J.-Y. Wu and P.-Y. Cheng, J. Phys. Chem. A, 2019, 123, 10700-10713.

36 H. Studzinski, S. Zhang, Y. Wang and F. Temps, J. Chem. Phys., 2008, 128, 164314.

37 S. Trushin, K. Kosma, W. Fuß and W. Schmid, Chem. Phys., 2008, 347, 309-323.

38 K. Kosma, S. A. Trushin, W. Fuß, W. E. Schmid and B. M. R. Schneider, Phys. Chem. Chem. Phys., 2010, 12, 13197-13214.

39 R. Montero, Á. P. Conde, V. Ovejas, M. Fernández-Fernández, F. Castaño and A. Longarte, J. Phys. Chem. A, 2012, 116, 10752-10758.

40 R. Montero, Á. Peralta Conde, V. Ovejas, M. FernándezFernández, F. Castaño, J. R. Vázquez de Aldana and A. Longarte, J. Chem. Phys., 2012, 137, 064317.

41 J. A. Green, D. V. Makhov, N. C. Cole-Filipiak, C. Symonds, V. G. Stavros and D. V. Shalashilin, Phys. Chem. Chem. Phys., 2019, 21, 3832-3841.

42 A. D. Tasker, L. Robson, K. W. D. Ledingham, T. McCanny, S. M. Hankin, P. McKenna, C. Kosmidis, D. A. Jaroszynski and D. R. Jones, J. Phys. Chem. A, 2002, 106, 4005-4013.

43 C. Mullen, M. J. Coggiola and H. Oser, J. Am. Soc. Mass Spectrom., 2009, 20, 419-429.

44 T. D. Scarborough, C. J. McAcy, J. Beck and C. J. G. J. Uiterwaal, Phys. Chem. Chem. Phys., 2019, 21, 6553-6558.

45 C. Kosmidis, K. W. D. Ledingham, H. S. Kilic, T. McCanny, R. P. Singhal, A. J. Langley and W. Shaikh, J. Phys. Chem. A, 1997, 101, 2264-2270.

46 M. J. Frisch, G. W. Trucks, H. B. Schlegel, G. E. Scuseria, M. A. Robb, J. R. Cheeseman, G. Scalmani, V. Barone, 
G. A. Petersson, H. Nakatsuji, X. Li, M. Caricato, A. V. Marenich, J. Bloino, B. G. Janesko, R. Gomperts, B. Mennucci, H. P. Hratchian, J. V. Ortiz, A. F. Izmaylov, J. L. Sonnenberg, D. Williams-Young, F. Ding, F. Lipparini, F. Egidi, J. Goings, B. Peng, A. Petrone, T. Henderson, D. Ranasinghe, V. G. Zakrzewski, J. Gao, N. Rega, G. Zheng, W. Liang, M. Hada, M. Ehara, K. Toyota, R. Fukuda, J. Hasegawa, M. Ishida, T. Nakajima, Y. Honda, O. Kitao, H. Nakai, T. Vreven, K. Throssell, J. A. Montgomery, Jr., J. E. Peralta, F. Ogliaro, M. J. Bearpark, J. J. Heyd, E. N. Brothers, K. N. Kudin, V. N. Staroverov, T. A. Keith, R. Kobayashi, J. Normand, K. Raghavachari, A. P. Rendell, J. C. Burant, S. S. Iyengar, J. Tomasi, M. Cossi, J. M. Millam, M. Klene, C. Adamo, R. Cammi, J. W. Ochterski, R. L. Martin, K. Morokuma, O. Farkas, J. B. Foresman and D. J. Fox, Gaussian 16 Revision C.01, Gaussian Inc., Wallingford, CT, 2016.

47 K. Burke, J. P. Perdew and Y. Wang, Electronic Density Functional Theory: Recent Progress and New Directions, Springer, US, New York, 1998, pp. 81-111.

48 R. Krishnan, J. S. Binkley, R. Seeger and J. A. Pople, J. Chem. Phys., 1980, 72, 650-654.

49 A. D. Becke, J. Chem. Phys., 1993, 98, 5648-5652.

50 C. Lee, W. Yang and R. G. Parr, Phys. Rev. B: Condens. Matter Mater. Phys., 1988, 37, 785-789.

51 Y. Zhao, Y. Zhao, D. G. Truhlar and D. G. Truhlar, Theor. Chem. Acc., 2008, 120, 215-241.

52 T. Yanai, D. P. Tew and N. C. Handy, Chem. Phys. Lett., 2004, 393, 51-57.

53 J.-D. Chai and M. Head-Gordon, Phys. Chem. Chem. Phys., 2008, 10, 6615-6620.

54 J. A. Montgomery, M. J. Frisch, J. W. Ochterski and G. A. Petersson, J. Chem. Phys., 1999, 110, 2822-2827.

55 T. H. Dunning, J. Chem. Phys., 1989, 90, 1007-1023.

56 F. Weigend and R. Ahlrichs, Phys. Chem. Chem. Phys., 2005, 7, 3297-3305.

57 F. W. McLafferty, P. F. Bente, R. Kornfeld, S.-C. Tsai and I. Howe, J. Am. Chem. Soc., 1973, 95, 2120-2129.

58 J. W. Rabalais, J. Chem. Phys., 1972, 57, 960-967.

59 A. I. Krylov, Annu. Rev. Phys. Chem., 2008, 59, 433-462.

60 Y. Shao, Z. Gan, E. Epifanovsky, A. T. Gilbert, M. Wormit, J. Kussmann, A. W. Lange, A. Behn, J. Deng, X. Feng, D. Ghosh, M. Goldey, P. R. Horn, L. D. Jacobson, I. Kaliman, R. Z. Khaliullin, T. Kuś, A. Landau, J. Liu, E. I. Proynov, Y. M. Rhee, R. M. Richard, M. A. Rohrdanz, R. P. Steele, E. J. Sundstrom, H. L. W. III, P. M. Zimmerman, D. Zuev, B. Albrecht, E. Alguire, B. Austin, G. J. O. Beran, Y. A. Bernard, E. Berquist, K. Brandhorst, K. B. Bravaya,
S. T. Brown, D. Casanova, C.-M. Chang, Y. Chen, S. H. Chien, K. D. Closser, D. L. Crittenden, M. Diedenhofen, R. A. D. Jr., H. Do, A. D. Dutoi, R. G. Edgar, S. Fatehi, L. Fusti-Molnar, A. Ghysels, A. Golubeva-Zadorozhnaya, J. Gomes, M. W. Hanson-Heine, P. H. Harbach, A. W. Hauser, E. G. Hohenstein, Z. C. Holden, T.-C. Jagau, H. Ji, B. Kaduk, K. Khistyaev, J. Kim, J. Kim, R. A. King, P. Klunzinger, D. Kosenkov, T. Kowalczyk, C. M. Krauter, K. U. Lao, A. D. Laurent, K. V. Lawler, S. V. Levchenko, C. Y. Lin, F. Liu, E. Livshits, R. C. Lochan, A. Luenser, P. Manohar, S. F. Manzer, S.-P. Mao, N. Mardirossian, A. V. Marenich, S. A. Maurer, N. J. Mayhall, E. Neuscamman, C. M. Oana, R. Olivares-Amaya, D. P. O’Neill, J. A. Parkhill, T. M. Perrine, R. Peverati, A. Prociuk, D. R. Rehn, E. Rosta, N. J. Russ, S. M. Sharada, S. Sharma, D. W. Small, A. Sodt, T. Stein, D. Stück, Y.-C. Su, A. J. Thom, T. Tsuchimochi, V. Vanovschi, L. Vogt, O. Vydrov, T. Wang, M. A. Watson, J. Wenzel, A. White, C. F. Williams, J. Yang, S. Yeganeh, S. R. Yost, Z.-Q. You, I. Y. Zhang, X. Zhang, Y. Zhao, B. R. Brooks, G. K. Chan, D. M. Chipman, C. J. Cramer, W. A. G. III, M. S. Gordon, W. J. Hehre, A. Klamt, H. F. S. III, M. W. Schmidt, C. D. Sherrill, D. G. Truhlar, A. Warshel, X. Xu, A. Aspuru-Guzik, R. Baer, A. T. Bell, N. A. Besley, J.-D. Chai, A. Dreuw, B. D. Dunietz, T. R. Furlani, S. R. Gwaltney, C.-P. Hsu, Y. Jung, J. Kong, D. S. Lambrecht, W. Liang, C. Ochsenfeld, V. A. Rassolov, L. V. Slipchenko, J. E. Subotnik, T. V. Voorhis, J. M. Herbert, A. I. Krylov, P. M. Gill and M. Head-Gordon, Mol. Phys., 2015, 113, 184-215.

61 http://webbook.nist.gov/chemistry/, last checked 7/17/20.

62 R. Bauernschmitt and R. Ahlrichs, Chem. Phys. Lett., 1996, 256, 454-464.

63 D. Ampadu Boateng and K. M. Tibbetts, JoVE, 2018, 138, e58263. 64 G. L. Gutsev, D. Ampadu Boateng, P. Jena and K. M. Tibbetts, J. Phys. Chem. A, 2017, 121, 8414-8424.

65 T. S. Rose, M. J. Rosker and A. H. Zewail, J. Chem. Phys., 1989, 91, 7415-7436.

66 T. Nishimura, P. R. Das and G. G. Meisels, J. Chem. Phys., 1986, 84, 6190-6199.

67 S. Grimme and M. Parac, ChemPhysChem, 2003, 4, 292-295.

68 K. Lopata, R. Reslan, M. Kowalska, D. Neuhauser, N. Govind and K. Kowalski, J. Chem. Theory Comput., 2011, 7, 3686-3693.

69 A. Prlj, B. F. E. Curchod, A. Fabrizio, L. Floryan and C. Corminboeuf, J. Phys. Chem. Lett., 2015, 6, 13-21.

70 A. Prlj, M. E. Sandoval-Salinas, D. Casanova, D. Jacquemin and C. Corminboeuf, J. Chem. Theory Comput., 2016, 12, 2652-2660.

71 A. Acharya, S. Chaudhuri and V. S. Batista, J. Chem. Theory Comput., 2018, 14, 867-876. 